\title{
BMJ Open Availability and use of continuous positive airway pressure (CPAP) for neonatal care in public health facilities in India: a cross-sectional cluster survey
}

Juan Emmanuel Dewez (D) , ${ }^{1}$ Sushma Nangia, ${ }^{2}$ Harish Chellani, ${ }^{3}$ Sarah White (D) , ${ }^{4}$ Matthews Mathai (D) , ${ }^{4}$ Nynke van den Broek ${ }^{4}$

To cite: Dewez JE, Nangia S, Chellani $\mathrm{H}$, et al. Availability and use of continuous positive airway pressure (CPAP) for neonatal care in public health facilities in India: a cross-sectional cluster survey. BMJ Open 2020;10:e031128. doi:10.1136/ bmjopen-2019-031128

- Prepublication history and additional material for this paper are available online. To view these files, please visit the journal online (http://dx.doi. org/10.1136/bmjopen-2019031128).

Received 17 April 2019 Revised 16 December 2019 Accepted 04 February 2020

Check for updates

(c) Author(s) (or their employer(s)) 2020. Re-use permitted under CC BY-NC. No commercial re-use. See rights and permissions. Published by BMJ.

For numbered affiliations see end of article.

Correspondence to Professor Matthews Mathai; Matthews.Mathai@Istmed.ac.uk

\section{ABSTRACT}

Objectives To determine the availability of continuous positive airway pressure (CPAP) and to provide an overview of its use in neonatal units in government hospitals across India.

Setting Cross-sectional cluster survey of a nationally representative sample of government hospitals from across India.

Primary outcomes Availability of CPAP in neonatal units. Secondary outcomes Proportion of hospitals where infrastructure and processes to provide CPAP are available. Case fatality rates and complication rates of neonates treated with CPAP.

Results Among 661 of 694 government hospitals with neonatal units that provided information on availability of CPAP for neonatal care, $68.3 \%$ of medical college hospitals (MCH) and $36.6 \%$ of district hospitals (DH) used CPAP in neonates. Assessment of a representative sample of 142 hospitals (79 $\mathrm{MCH}$ and $63 \mathrm{DH}$ ) showed that air-oxygen blenders were available in $50.7 \%(95 \% \mathrm{Cl} 41.4 \%$ to $60.9 \%)$ and staff trained in the use of CPAP were present in $56.0 \%$ (45.8\% to $65.8 \%)$ of hospitals. The nurse to patient ratio was 7.3 (6.4 to 8.5) in $\mathrm{MCH}$ and 6.6 (5.5 to 8.3) in $\mathrm{DH}$. Clinical guidelines were available in $31.0 \%$ of hospitals (22.2\% to $41.4 \%$ ). Upper oxygen saturation limits of above $94 \%$ were used in $72 \%$ (59.8\% to $81.6 \%$ ) of $\mathrm{MCH}$ and $59.3 \%$ (44.6\% to $72.5 \%$ ) of $\mathrm{DH}$. Respiratory circuits were reused in $53.8 \%$ (42.3\% to $63.9 \%$ ) of hospitals. Case fatality rate for neonates treated with CPAP was $21.4 \%$ (16.6\% to $26.2 \%)$; complication rates were $0.7 \%(0.2 \%$ to $1.2 \%)$ for pneumothorax, $7.4 \%(0.9 \%$ to $13.9 \%)$ for retinopathy and $1.4 \%(0.7 \%$ to $2.1 \%)$ for bronchopulmonary dysplasia. Conclusions CPAP is used in neonatal units across government hospitals in India. Neonates may be overexposed to oxygen as the means to detect and treat consequences of oxygen toxicity are insufficient. Neonates may also be exposed to nosocomial infections by reuse of disposables. Case fatality rates for neonates receiving CPAP are high. Complications might be under-reported. Support to infrastructure, training, guidelines implementation and staffing are needed to improve CPAP use.

\section{INTRODUCTION}

An estimated 2.9 million neonates die every year worldwide. Most of these deaths are in
Strengths and limitations of this study

- Nationwide assessment of the availability and use of continuous positive airway pressure (CPAP) in neonates in a representative sample of public hospitals in India, through direct hospital site visits.

- Our findings apply to government facilities; the availability and use of CPAP in private hospitals, where a large proportion of inpatient care is provided in India, may be different.

- The standards used to assess the availability of essential infrastructures and processes to provide CPAP were decided by consensus among the research team, and this carries a degree of subjectivity.

- Data about infrastructures and processes were based on participants' reports, and there might have been reporting bias.

- Data on some important determinants of neonatal mortality and morbidity were not collected, which precludes firm conclusions on the impact of lack of infrastructures and processes on the clinical outcomes reported.

low-income and middle-income countries (LMIC) and result from prematurity, intrapartum-related conditions and infections. ${ }^{1}$ Acute respiratory distress, common to these causes of death, is associated with case fatality rates as high as $20 \%$ in $\mathrm{LMIC}^{2}{ }^{2}$ The most basic respiratory support for neonates with acute respiratory distress is oxygen, followed by non-invasive support such as continuous positive airway pressure (CPAP), and by mechanical ventilation. Mechanical ventilation involves endotracheal intubation, an invasive procedure requiring high technical skills. In contrast, CPAP can in principle be applied by non-specialist healthcare providers. ${ }^{3}$ It is estimated that the use of oxygen in combination with CPAP for the treatment of respiratory distress contributed to a $70 \%$ increase in the survival of preterm babies in high-income countries. 4 Several studies reported that 
CPAP is safe and effective in LMIC and its use in these settings is increasing. ${ }^{5-12}$

However, CPAP use can lead to serious complications such as pneumothorax, or nasal trauma. ${ }^{13} 14$ Moreover, when CPAP is used with supplemental oxygen, the unregulated use of oxygen may lead to retinopathy of prematurity (ROP) ${ }^{15}$ a major cause of blindness, or bronchopulmonary dysplasia (BPD) ${ }^{16}$

CPAP is easy to initiate, but to be effective, CPAP needs to be used continuously for hours or days. This implies continuous supplies of electricity and medical gases, continuous clinical monitoring for timely detection of acute complications and long-term follow-up for chronic complications. Consequently, the WHO recommends considering the wider context of care prior to introducing and scaling-up CPAP use in LMIC. ${ }^{17}$

India accounts for an estimated 779000 neonatal deaths every year. ${ }^{1}$ The Government of India has launched several initiatives to reduce neonatal mortality. These include the establishment of Special Newborn Care Units (SNCU) which provide level II care including treatment for sepsis, jaundice and respiratory distress. SNCU have been implemented in district hospitals (DH), that is, secondary care hospitals, and in medical college hospitals (MCH), that is, tertiary care hospitals. ${ }^{18}$ The current national recommendations in terms of respiratory support are to use oxygen in DH, and CPAP and mechanical ventilation in $\mathrm{MCH} .{ }^{19}$ However, CPAP seems to be used in $\mathrm{DH} .{ }^{20}$ The extent of CPAP use in neonates at the different levels of care, the availability of structures and processes to enable its use, and the clinical outcomes of this intervention in India are unclear.

The aims of this study were to determine the availability of CPAP and to provide an overview of its use in neonatal units in government hospitals across India.

\section{METHODS}

\section{Study design}

A cross-sectional cluster survey was conducted among neonatal units using CPAP in government hospitals in India.

\section{Identification of hospitals using CPAP in neonates}

Programme officers responsible for neonatal health in all Indian states and union territories were contacted to obtain a list of all government $\mathrm{MCH}$ and $\mathrm{DH}$ with SNCU or neonatal intensive care unit (NICU). NICU are neonatal units in $\mathrm{MCH}$ that existed before the central government launched the initiative to implement SNCU in DH and MCH. All hospitals with a SNCU/NICU were subsequently contacted to enquire whether CPAP was used in the neonatal unit.

\section{Selection of hospitals}

Hospitals were selected for inclusion in the study using stratified cluster random sampling. Stratification was by:
1. District performance ranking based on a composite health index developed by the Government of India to identify districts needing priority investments in healthcare ${ }^{21}$ High priority districts were defined as the bottom $25 \%$ of districts for health index scores; nonhigh priority districts were those in the top $75 \%$.

2. Type of neonatal unit-NICU or SNCU. NICU are funded and monitored by state governments. SNCU are funded and monitored by the central government. Because of these differences, we initially considered three types of neonatal units: NICU in $\mathrm{MCH}, \mathrm{SNCU}$ in $\mathrm{MCH}$ and SNCU in DH.

Prior to sample selection, facilities within the two strata determined by district performance were assigned to 62 clusters, typically either as a state or a subset of the districts within a state. Within each of the clusters there were between 3 and 10 facilities providing CPAP. These clusters were then stratified by type of neonatal unit.

Random sampling (among the 62 clusters) was stratified to ensure that the margin of error in each of the three facility-type strata did not exceed $10 \%$, assuming the ICC did not exceed 0.1. A list of 42 randomly selected clusters was generated using the Runiform function in Stata with a sequence for inclusion of hospitals within the clusters until the planned sample size (see below) in each of the three strata was achieved.

\section{Sample size}

We initially estimated that the sample sizes of neonatal units required to estimate the outcomes of interest with $95 \%$ CI and a margin of error not exceeding $10 \%$ would be:

- 36 NICU in MCH.

- 51 SNCU in MCH.

- 76 SNCU in DH.

However, during data collection, it became evident that NICU and SNCU in MCH were not substantially different in organisation (eg, staff deployment, purchasing and maintenance of equipment) or provision of neonatal healthcare (eg, the same clinical guidelines where available were used). Therefore, it was decided to combine NICU and SNCU into a single stratum (called neonatal units in $\mathrm{MCH}$ ). Treating them as one stratum for sampling, the sample size was revised to:

- 62 neonatal units in MCH.

- 76 neonatal units in $\mathrm{DH}$.

\section{Data collection}

Data were collected using a structured questionnaire and an observational checklist. The questionnaire (available as online supplementary data) included 136 questions pertaining to availability of structures (infrastructure such as equipment, staffing), processes (practice of care) and outcomes (clinical outcomes) related to CPAP use, following the Donabedian framework for assessing quality of healthcare. ${ }^{22}$ The questionnaire was developed based on 11 guidelines from four countries (India, the United Kingdom, Australia and Spain) identified through a 
review of the literature. As there were no international standards for CPAP use in neonates, the research team (which included neonatologists, paediatricians and obstetricians) developed by consensus, a set of 21 standards for structures and 12 standards for processes. The questionnaire allowed collecting data on 17 standards for structures and all 12 standards for processes. The observational checklist allowed for direct observation of four of the remaining structures standards. Data collection tools were finalised after pilot tests in two hospitals in Delhi.

Data were collected during site visits to each hospital by paediatric trainees or senior paediatricians who had been trained and had participated in pilot testing of data collection tools. In each hospital, doctors and nurses who were present on the day of the visit answered questions on structures that were not observable (eg, the availability of a doctor in the neonatal unit 24/7) and processes. Data for all neonates treated with CPAP during the 3 months preceding the visit were extracted from registers/records to assess clinical outcomes. Following this, the neonatal unit was visited and assessed using the observational checklist to assess availability of observable structures.

All assessments were conducted between May and September 2016. Data were collected electronically on iPads.

\section{Statistical analysis}

Descriptive statistics were derived with sampling errors, to provide $95 \%$ CIs, that account for the variation in sizes and values for the clusters sampled. The analysis was performed with SPSS 23.0. On average, data for infrastructure, practice of care and clinical outcomes were missing from $0.8 \%, 8.5 \%$ and $44 \%$ of hospitals, respectively. Missing data for infrastructure and practice of care were considered as 'item not available in the hospital', while missing data for outcomes were not considered in the analysis.

To examine whether facilities with better infrastructure and practice of delivering CPAP have lower case fatality rates, we carried out an additional analysis: an index was defined which measures the proportion of 18 infrastructure criteria (all infrastructure criteria, except availability of BPD, ROP screening and ROP treatment, as these criteria do not have direct impact on immediate mortality) and the 12 practices criteria met at each facility. A hospital with all criteria met would have an index of 1 , while a hospital with no criteria met, an index of 0 . This index was then used as a covariate in logistic regression analysis for case fatality rates of newborns treated with CPAP. The analysis was weighted to account for the variation in numbers of cases between facilities. Estimates are reported as odd ratios with corresponding $95 \%$ CI. The additional analysis was performed using Stata V.15.

\section{Patient and public involvement}

There was no patient or public involvement.

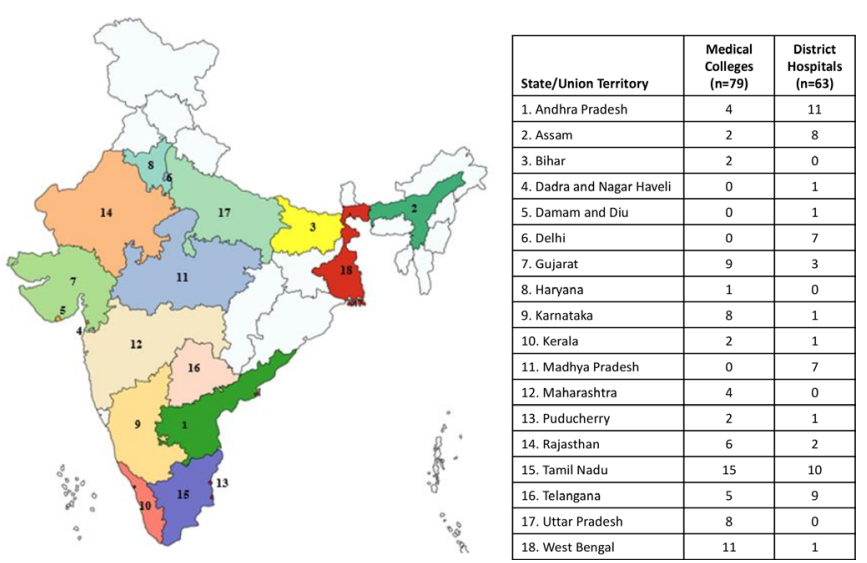

Figure 1 Hospitals from Indian states and union territories included in the assessment.

\section{RESULTS}

\section{Availability of CPAP}

In total, 232 neonatal units in $\mathrm{MCH}$ and 462 in $\mathrm{DH}$ were identified across the states. Information on whether the neonatal unit used CPAP could not be obtained for $12.9 \%$ $(30 / 232)$ of $\mathrm{MCH}$ and $0.6 \%(3 / 462)$ of DH. Overall 138 of 202 neonatal units at MCH $(68.3 \%)$ and 168 of 459 neonatal units at DH (36.6\%) used CPAP. Of these, 142 neonatal units (79 at $\mathrm{MCH}$ and 63 at $\mathrm{DH}$ ) from 33/62 clusters in 18 states and union territories were assessed (figure 1). Twenty-one facilities (8 MCH and $13 \mathrm{DH})$ from 6 of the 33 sampled clusters could not be assessed because of time constraints and local events (strikes, political unrest). Thus, there was a $17 \%$ shortfall in the planned number of DH facilities (76) but an excess for MCH.

\section{Infrastructure for CPAP}

Forty-six MCH $(58.2 \%, 95 \%$ CI $44.6 \%$ to $70.7 \%)$ and $44 \mathrm{DH}(69.8 \%, 95 \%$ CI $54.1 \%$ to $82 \%)$ used commercial CPAP machines exclusively. These included bubble CPAPs, infant flow CPAP systems, mechanical ventilators with CPAP mode, or high flow nasal cannula systems. Bubble CPAP was the most common system: $87.3 \%$ (95\% CI $80.3 \%$ to $92.1 \%$ ) of all hospitals used this system (see online supplementary data for more details on other systems). The remaining hospitals used a mixture of commercial and indigenous (home-made) devices.

General infrastructure (ie, electricity, medical gases) was usually available, although $23.6 \%$ of hospitals did not have access to technical maintenance for CPAP equipment. None of the hospitals met all the stipulated standards for infrastructure (table 1).

\section{Standard of practice}

In general, practice was in line with standards regarding general monitoring of a neonate receiving CPAP, except for continuous monitoring of respiratory rate and assessment of respiratory distress which were practised in about half of all hospitals (table 2). A predefined oxygen saturation range was used in $94.9 \%$ of $\mathrm{MCH}$ and $92.1 \%$ of $\mathrm{DH}$. Of these, $72 \%$ (95\% CI $59.8 \%$ to $81.6 \%$ ) of $\mathrm{MCH}$ and $59.3 \%$ ( $95 \%$ CI $44.6 \%$ to $72.5 \%$ ) of $\mathrm{DH}$ reported using 
Table 1 Availability of infrastructure for continuous positive airway pressure (CPAP) at medical college hospitals (MCH, $n=79$ ), district hospitals $(\mathrm{DH}, \mathrm{n}=63)$ and for both combined $(n=142)$

\begin{tabular}{|c|c|c|}
\hline Type of hospital & & \\
\hline $\begin{array}{l}\text { Medical college } \\
\text { hospitals }(n=79)\end{array}$ & District hospitals $(n=63)$ & $\begin{array}{l}\text { Total } \\
(\mathrm{n}=142)\end{array}$ \\
\hline$\%(95 \% \mathrm{Cl})$ & $\%(95 \% \mathrm{Cl})$ & $\%(95 \% \mathrm{Cl})$ \\
\hline
\end{tabular}

\section{Essential infrastructure}

General infrastructure

\begin{tabular}{|c|c|c|c|}
\hline Technical maintenance & $77.2(66.0$ to 85.6$)$ & 73.0 (57.0 to 84.7$)$ & 75.4 (66.2 to 82.6$)$ \\
\hline Emergency electricity source & 93.7 (87.3 to 97.0$)$ & $87.3(68.8$ to 95.6$)$ & 90.8 (82.3 to 95.5$)$ \\
\hline Air and oxygen & $91.1(83.0$ to 95.6$)$ & 88.9 (73.8 to 95.8$)$ & 90.1 (82.8 to 94.5$)$ \\
\hline \multicolumn{4}{|l|}{ CPAP-specific infrastructure } \\
\hline Air-oxygen blender for each CPAP device & 51.9 (39.7 to 63.8$)$ & 49.2 (32.6 to 66.0$)$ & 50.7 (41.4 to 60.9$)$ \\
\hline Range of sizes of nasal interfaces & 86.1 (75.6 to 92.5$)$ & 87.3 (76.4 to 93.6$)$ & 86.6 (79.6 to 91.5$)$ \\
\hline $\begin{array}{l}\text { Guidelines for CPAP use available in the } \\
\text { immediate area of care }\end{array}$ & 27.8 (19.4 to 38.2$)$ & 34.9 (19.5 to 54.3$)$ & $31.0(22.2$ to 41.4$)$ \\
\hline \multicolumn{4}{|l|}{ Staffing levels } \\
\hline$\geq 1$ doctor $24 / 7$ & $93.7(85.0$ to 97.5$)$ & $65.1(44.8$ to 81.1$)$ & 81.0 (69.6 to 88.8$)$ \\
\hline$\geq 1$ doctor $24 / 7$ trained in CPAP use & 63.3 (51.7 to 73.5$)$ & 46.8 (29.8 to 64.5$)$ & 56.0 (45.8 to 65.8$)$ \\
\hline $\begin{array}{l}\geq 1 \text { doctor technically competent in the } \\
\text { management of pneumothorax available } 24 / 7\end{array}$ & 75.9 (64.5 to 84.6$)$ & 41.3 (25.7 to 58.8$)$ & 60.6 (49.9 to 70.3$)$ \\
\hline CPAP training plan available & 48.1 (34.3 to 62.2) & $41.3(25.7$ to 58.8$)$ & 45.1 (34.4 to 56.2 ) \\
\hline \multicolumn{4}{|l|}{ Monitoring } \\
\hline Neonatal pulse oximeters & 82.3 (72.2 to 89.2$)$ & 93.7 (85.3 to 97.4$)$ & 87.3 (80.9 to 91.8$)$ \\
\hline X-ray $24 / 7$ & 86.1 (77.4 to 91.8$)$ & 54.0 (35.0 to 71.9$)$ & 71.8 (60.6 to 80.9$)$ \\
\hline Transilluminator & 17.7 (10.4 to 28.7$)$ & 6.3 (1.5 to 23.5$)$ & 12.7 (7.4 to 20.9$)$ \\
\hline Retinopathy of prematurity (ROP) screening & 89.9 (77.2 to 95.9$)$ & $60.3(44.0$ to 75.6$)$ & 76.8 (66.0 to 84.9$)$ \\
\hline Broncho-pulmonary dysplasia (BPD) screening & 62.0 (49.0 to 73.5$)$ & 22.2 (12.5 to 36.3$)$ & 44.4 (34.8 to 54.4$)$ \\
\hline \multicolumn{4}{|l|}{ Management of complications } \\
\hline $\begin{array}{l}\text { Availability of equipment specific to the } \\
\text { management of neonatal pneumothorax }\end{array}$ & $63.3(49.8$ to 74.9$)$ & $20.6(9.8$ to 38.3$)$ & 44.4 (34.1 to 55.2$)$ \\
\hline \multicolumn{4}{|l|}{ Other important infrastructure } \\
\hline Availability of caffeine & 82.3 (71.6 to 89.5$)$ & $58.7(40.3$ to 75.0$)$ & $71.8(60.3$ to 81.1$)$ \\
\hline Availability of surfactant & 77.2 (66.6 to 85.2$)$ & 49.2 (31.9 to 66.8$)$ & 64.8 (53.5 to 74.6$)$ \\
\hline Availability of humidifiers & 55.7 (43.1 to 67.6$)$ & 63.5 (48.8 to 76.1$)$ & 59.2 (49.6 to 68.0$)$ \\
\hline Availability of antenatal corticosteroids & 93.7 (85.7 to 97.3$)$ & 85.7 (75.9 to 91.9$)$ & 90.1 (84.6 to 93.8 ) \\
\hline $\begin{array}{l}\text { Availability of cryotherapy or laser therapy for } \\
\text { the treatment of ROP }\end{array}$ & 44.3 (30.9 to 58.5$)$ & $7.9(2.9$ to 20.0$)$ & 28.2 (19.4 to 39.0$)$ \\
\hline
\end{tabular}

the treatment of ROP

an upper oxygen saturation limit of above $94 \%$ (figure 2). Processes followed less often were those related to infection prevention; for example, single use of respiratory circuits was practised in only $46.8 \%$ (95\% CI $34.0 \%$ to $60.1 \%$ ) of $\mathrm{MCH}$ and $47.6 \%$ (95\% CI $31.5 \%$ to $64.2 \%$ ) of $\mathrm{DH}$. Two DH met all the standards for practice.

\section{Clinical outcomes}

Overall case fatality rates (CFR) for neonates admitted to neonatal units were $13.2 \%$ (95\% CI $10.7 \%$ to $15.7 \%$ ) in $\mathrm{MCH}$ and $7.4 \%$ (95\% CI $5.7 \%$ to $9.1 \%)$ in DH. The case fatality rate among neonates treated with CPAP in $\mathrm{MCH}$ and $\mathrm{DH}$ were
$19.8 \%$ (95\% CI $14.6 \%$ to $24.9 \%$ ) and $26.3 \%$ (95\% CI $15.7 \%$ to $37.0 \%$ ), respectively. The most commonly reported complication in $\mathrm{MCH}$ was ROP $(8.4 \%$; $95 \%$ CI $0.7 \%$ to $16.1 \%)$. At DH level, nasal lesions were the most frequently reported complication $(5.7 \%$; $95 \%$ CI $1.1 \%$ to $10.3 \%$ ) (table 3 ).

In terms of the relationship between the availability of infrastructures, the practice of providing CPAP, and CFR, the CFR of hospitals with more infrastructure and practices was not significantly different from the CFR of hospitals with less infrastructure and practices in place (OR 4.65, 95\% CI 0.46 to $47.2, \mathrm{p}=0.30$ ). 
Table 2 Practice of providing continuous positive airway pressure (CPAP) against process standards in medical college hospitals, district hospitals and for both combined $(n=142)$

\begin{tabular}{|c|c|c|c|}
\hline & \multicolumn{2}{|c|}{ Type of neonatal unit } & \multirow[b]{2}{*}{$\begin{array}{l}\text { Total } \\
(\mathrm{n}=142) \\
\%(95 \% \mathrm{Cl})\end{array}$} \\
\hline & $\begin{array}{l}\text { Medical college } \\
\text { hospitals }(n=79) \\
\%(95 \% \mathrm{Cl})\end{array}$ & $\begin{array}{l}\text { District hospitals } \\
(\mathrm{n}=63) \\
\%(95 \% \mathrm{Cl})\end{array}$ & \\
\hline \multicolumn{4}{|l|}{ Essential processes } \\
\hline \multicolumn{4}{|l|}{ General clinical monitoring } \\
\hline Continuous monitoring of oxygen saturation & 88.6 (79.5 to 94.0$)$ & 92.1 (82.9 to 96.5$)$ & 90.1 (84.1 to 94.0$)$ \\
\hline Continuous monitoring of respiratory rate & 60.8 (45.2 to 74.4$)$ & 50.8 (37.4 to 64.1$)$ & 56.3 (45.8 to 66.3$)$ \\
\hline Regular assessment of respiratory distress & 40.5 (30.1 to 51.8$)$ & 49.2 (30.8 to 67.8$)$ & 44.4 (34.3 to 54.9$)$ \\
\hline \multicolumn{4}{|l|}{ CPAP } \\
\hline Use of a predefined initial pressure level & 86.1 (78.4 to 91.3$)$ & 85.7 (71.6 to 93.5) & 85.9 (78.9 to 90.9$)$ \\
\hline Use of a standardised CPAP weaning process & 50.6 (38.4 to 62.8$)$ & $61.9(40.6$ to 79.4$)$ & $55.6(44.2$ to 66.5$)$ \\
\hline \multicolumn{4}{|l|}{ Infection prevention } \\
\hline Respiratory circuit replaced after 1 week of use & $38.0(27.3$ to 50.0$)$ & $47.6(28.2$ to 67.8$)$ & $42.3(31.5$ to 53.9$)$ \\
\hline Single use of respiratory circuits & 46.8 (34.0 to 60.1$)$ & 47.6 (31.5 to 64.2$)$ & $47.2(36.9$ to 57.7$)$ \\
\hline Single use of nasal interface & 41.8 (31.4 to 52.9$)$ & 47.6 (30.4 to 65.4$)$ & $44.4(34.7$ to 54.5$)$ \\
\hline
\end{tabular}

\section{DISCUSSION}

Two thirds of MCH and one third of DH use CPAP in neonates. No hospital met all 21 infrastructure standards, but two DH met all 12 standards for practice. A third of hospitals use home-made devices. Although general infrastructure (eg, electricity, medical gases and so on) is usually available, only half of all hospitals have air-oxygen blenders for every CPAP machine. Basic monitoring equipment is generally available. However, diagnostic equipment to identify complications of CPAP and/or to manage these is limited, especially at DH level. More than half of the hospitals reuse respiratory circuits or nasal interfaces. Most hospitals use predefined initial pressure levels and oxygen saturation ranges, but $72.0 \%$ of $\mathrm{MCH}$ and $59.3 \%$ of $\mathrm{DH}$ use upper oxygen saturation limits above $94 \%$. On average, one nurse provides care

\section{Medical College Hospitals}

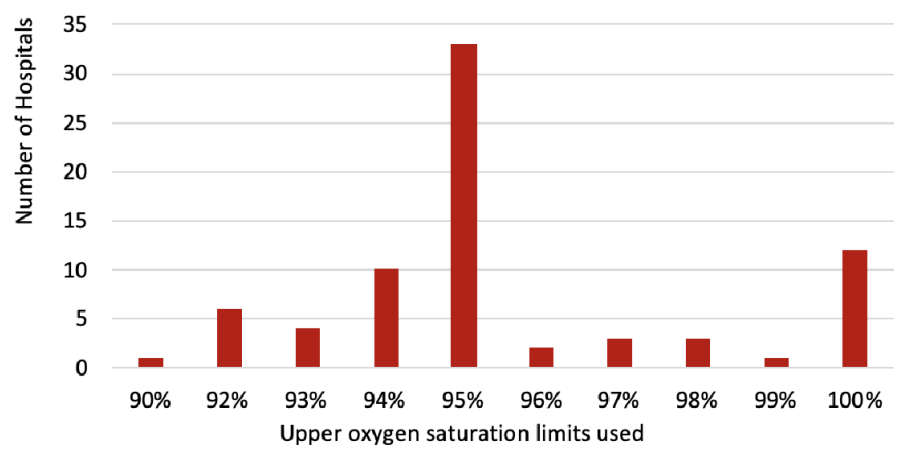

Figure 2 Upper oxygen saturation limits used. for seven neonates. Mortality rate for babies on CPAP is $21.4 \%$. Pneumothorax is reported in $<1 \%$, and ROP and $\mathrm{BPD}$ are reported in $7.4 \%$ and $1.4 \%$, respectively.

Our study identified several areas for improvement.

Not all hospitals follow the national recommendation that CPAP should be used only in MCH and not in DH.

Not all the infrastructure, manpower and skills needed to implement CPAP safely are in place. Some hospitals use home-made devices. Home-made devices are more likely to lack an air-oxygen blender for titration of oxygen; this increases the risk of oxygen toxicity. In line with our findings, a survey by Sundaram and colleagues found that only a third of neonatal units in India were equipped with air-oxygen blenders. ${ }^{23}$ Moreover, respiratory circuits and nasal interfaces are frequently reused, which can expose neonates to nosocomial infections.

\section{District Hospitals}

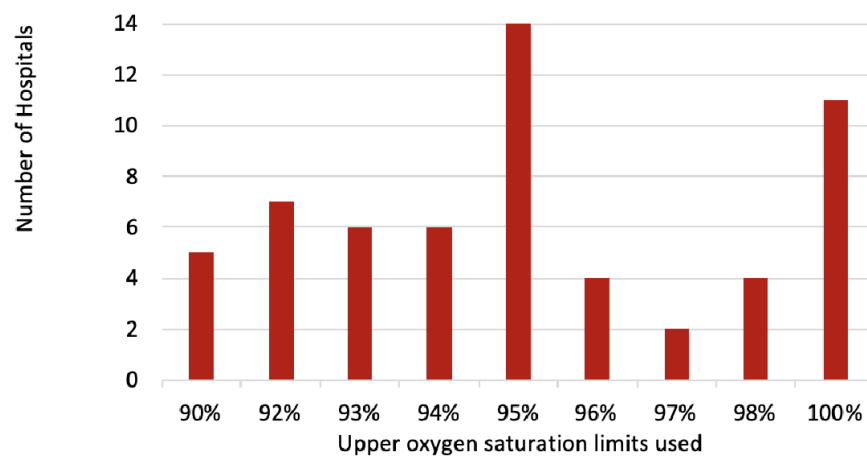




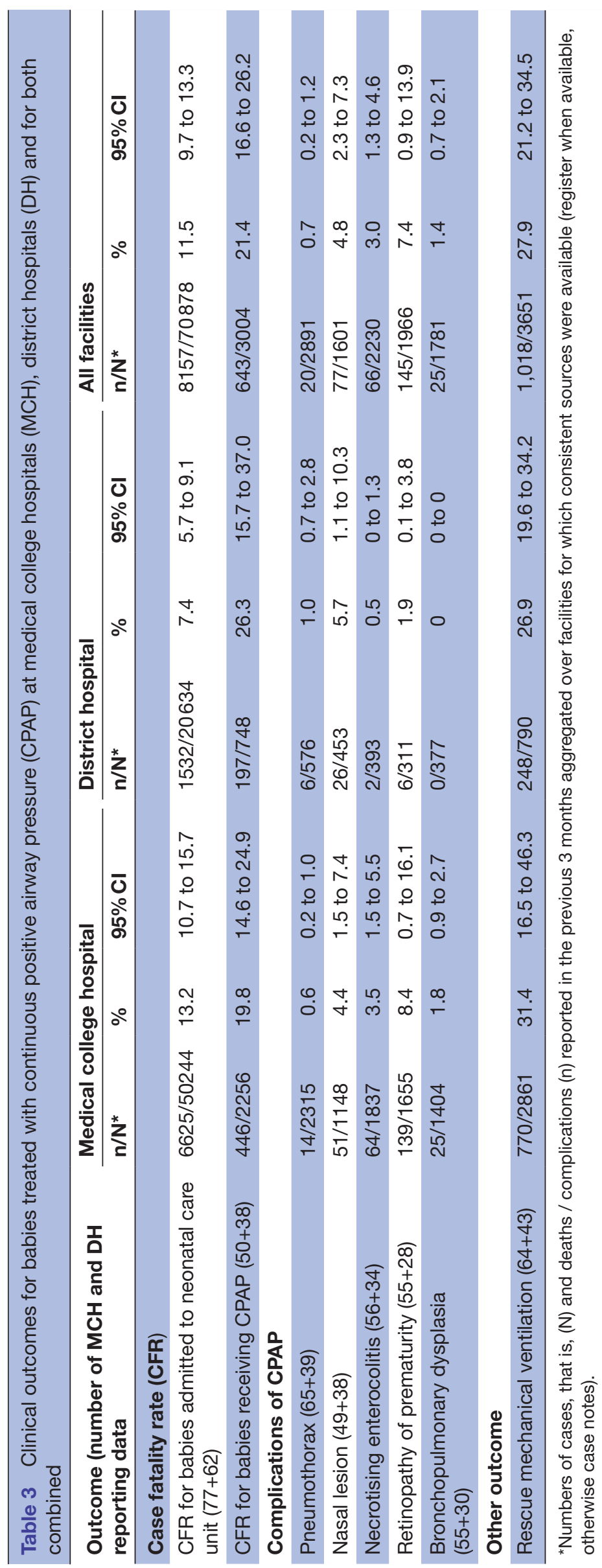


Circuits and interfaces cannot be autoclaved. Hence, in India, they are usually disinfected with activated glutaraldehyde solutions. Arai and colleagues in Brazil found that anaesthesia circuits were still colonised with pathogens in $39.3 \%$ of circuits after disinfection with activated glutaraldehyde solutions. ${ }^{24}$ Studies from England and the Netherlands have reported episodes of infection outbreaks in neonatal and paediatric intensive care units associated with reutilisation of respiratory consumables that were disinfected but not sterilised. ${ }^{25}{ }^{26}$ In terms of staffing, a nurse:patient ratio of 1:7 is problematic. It is less than the Indian standard of 1:4 for SNCUs,${ }^{19}{ }^{27}$ and insufficient for units providing CPAP. In high-income countries, the nurse:patient ratio for advanced care is $1: 2^{28}$ to ensure continuous clinical monitoring. Insufficient staffing has already been reported in the India Newborn Action Plan as a barrier to ensuring quality neonatal care. ${ }^{29}$ In terms of skills, the finding that most nurses report using upper oxygen saturation limits above $94 \%$ is a concern. The range to be used in neonates is subject to debate, ${ }^{30}$ but an upper oxygen saturation limit in preterm neonates of below $94 \%$ is recommended both internationally ${ }^{31}$ and nationally. ${ }^{19}$ The combination of the lack of air-oxygen blenders, the high number of patients monitored per nurse and the use of high upper oxygen saturation limits may expose neonates to excessive oxygen. ROP was indeed the most common complication reported in $\mathrm{MCH}$ and is a major health issue in India. ${ }^{32-37}$

The case fatality rate for neonates treated with CPAP in this study is in line with reports from India, ${ }^{98-43} \operatorname{Iran}^{11}$ and South Africa, ${ }^{84-46}$ but other countries, such as Fiji, ${ }^{6}$ Latin American countries ${ }^{7} 48$ and high-income countries $^{13}$ have reported lower mortality rates. The reported rate of pneumothorax in this study is similar to other studies from India ${ }^{98-40} 42$ and South Africa, ${ }^{44}$ but lower than in Latin America ${ }^{77}$ and Iran. ${ }^{12}$ The rate of ROP was lower than in other reports from India, ${ }^{31} 49$ Latin America $^{47}$ and Iran. ${ }^{12}$

The higher rate of mortality in neonates treated with CPAP in India may be a consequence of the lack of infrastructure and the shortfalls in the practices of care presented above, while the lower rates of complications could be linked to the lack of equipment to identify them. However, in our study, the CFR of neonates who received CPAP in better equipped hospitals was not significantly different to the CFR of less equipped hospitals.

\section{Strengths and limitations}

To the best of our knowledge, this is the first nation-wide assessment of the availability and use of CPAP in a representative sample of public hospitals in India. All units were assessed through site-visits. Our results should be interpreted considering some limitations. Our findings only apply to government facilities; the availability and use of CPAP in private hospitals, where a large proportion of inpatient care is provided in India, may be different. The selection of standards for CPAP use presented in this paper was decided by consensus and carries a degree of subjectivity. Data about infrastructure and practice of providing CPAP were based on participants' reports, and there might have been reporting bias. Clinical outcome data were obtained from existing records with some variability in the availability and quality of these. Finally, we did not collect data on important determinants of neonatal mortality and morbidity, such as gestational age, the severity of disease, nor on whether neonates had received surfactant or antenatal corticosteroids, which preclude making firm conclusions on the impact of shortfalls in infrastructure and practice of care on clinical outcomes.

\section{Implications for practice and further research}

While confirming and supporting the strong commitment of the Indian Government and healthcare providers to use an intervention that contributes to improved survival, it is important to take a relook at the current use of CPAP in neonatal units of public hospitals, the current national guidelines,${ }^{19}$ and the implications for scalability.

More MCH should use CPAP, and the recommendation of using CPAP should be expanded to DH as well. The current preference of a commercial bubble system should be supported, as this type of CPAP system is more likely to have in-built mechanisms to control pressure, air-oxygen mix, temperature and humidity of medical gases, and is less invasive than CPAP provided by mechanical ventilators. Neonatal units should have enough single-use consumables. Staff working in neonatal units should comply with recommendations when providing oxygen. More nurses should be made available to provide neonatal care, and further discussion and guidance are required to establish what the minimum nurse/patient ratio should be in the context of LMIC settings.

Ensuring all the above should improve the effectiveness of CPAP use. However, additional data such as the case mix of patients in terms of gestational age, severity of disease and comorbidities, as well as the use of surfactant and antenatal corticosteroids should be collected to better identify the determinants of clinical outcomes of CPAP use in India. Moreover, longitudinal studies, interrupted time studies and pragmatic randomised controlled trials are needed to assess the effectiveness of CPAP in improving neonatal clinical outcomes in the Indian context. Finally, international standards for CPAP use in neonates should be developed to guide the implementation, monitoring and evaluation of this intervention.

\section{CONCLUSIONS}

India is embracing the use of CPAP for neonatal care. While electricity, medical gases and basic monitoring equipment are widely available, further support is needed to ensure availability of trained staff, equipment to provide oxygen safely and sufficient quantities of disposables to avoid reuse. Neonates may be overexposed to oxygen, while the means to detect and treat the consequences of oxygen toxicity are insufficient. Neonates may also be exposed to nosocomial infections because of the reuse 
of disposables. Case fatality rates for neonates receiving CPAP are higher than in other countries, and complications might be under-reported. Additional studies are needed to identify the determinants of clinical outcomes when CPAP is used in neonates and to assess the effectiveness of this intervention in India.

\section{Author affiliations}

${ }^{1}$ Faculty of Infectious and Tropical Diseases, London School of Hygiene and Tropical Medicine, London, UK

${ }^{2}$ Department of Neonatology, Lady Hardinge Medical College and Kalawati Saran Hospital, New Delhi, Delhi, India

${ }^{3}$ Department of Pediatrics, Vardhman Mahavir Medical College and Safdarjung Hospital, New Delhi, Delhi, India

${ }^{4}$ Department of International Public Health, Centre for Maternal and Newborn Health, Liverpool School of Tropical Medicine, Liverpool, UK

Acknowledgements We are grateful to the following individuals for their help with site visits and assessments: Lady Hardinge Medical College: Sushma Nangia, Babu S Madarkar, Prathik B H, Tapas Bandyopadhyay, Viraraghavan V R, Debashish Nanda, Sandeep Jhajra, Anchala Singh, Yogesha K N, Sarfaraz R Momin, Sunita Namdev, Rajat Goswami, Abhimanyu Chowdhury, Kushagra Taneja, Suryaprakash. Safdarjung Hospital: Shobhana Gupta, Archana Kashyap, Murtaza Kamal, Vijaydeep. Government of Delhi: Lalan Kumar Bharti. We are grateful for the support received from Paul Francis and the WHO's office in India, Ajay Khera and P K Prabhakar Deputy Commissioners, Child Health Division, Ministry of Health and Family Welfare of India, and all the Programme Officers, Maternal and Child Health, from all Indian states. We also thank Ritu Agrawal, Senior Technical Officer, Liverpool School of Tropical Medicine for her support in project coordination in India. We are grateful to Mark Turner and his team at the Liverpool Women's NHS Foundation Trust for their suggestions about the content of the data collection materials. The map of India was created using MapChart (https://mapchart.net/) under the terms of the CC BY 4.0 License (Creative Commons Attribution-ShareAlike 4.0 International License).

Contributors JED conceptualised and designed the study, oversaw data collection, conducted the analyses, drafted the initial manuscript and revised the manuscript. NvdB and SW contributed to study design, data analyses and critical reviews of manuscripts. SN and HC contributed to study design, oversaw data collection and provided critical reviews of manuscripts. MM oversaw data collection and data analyses, critically reviewed, revised and finalised the manuscript. All authors approved the final manuscript as submitted and agree to be accountable for all aspects of the work.

Funding This work was supported by the World Health Organization, grant number: 2016/613341-0.

Map disclaimer The depiction of boundaries on this map does not imply the expression of any opinion whatsoever on the part of BMJ (or any member of its group) concerning the legal status of any country, territory, jurisdiction or area or of its authorities. This map is provided without any warranty of any kind, either express or implied.

Competing interests None declared.

Patient consent for publication Not required.

Ethics approval The study was approved by the Ministry of Health and Family Welfare of India and by the Liverpool School of Tropical Medicine's Research and Ethics Committee (Reference 15-032).

Provenance and peer review Not commissioned; externally peer reviewed.

Data availability statement Data are available upon reasonable request.

Open access This is an open access article distributed in accordance with the Creative Commons Attribution Non Commercial (CC BY-NC 4.0) license, which permits others to distribute, remix, adapt, build upon this work non-commercially, and license their derivative works on different terms, provided the original work is properly cited, appropriate credit is given, any changes made indicated, and the use is non-commercial. See: http://creativecommons.org/licenses/by-nc/4.0/.

\section{ORCID iDs}

Juan Emmanuel Dewez http://orcid.org/0000-0002-5677-8968

Sarah White http://orcid.org/0000-0001-5535-8075

Matthews Mathai http://orcid.org/0000-0002-7352-9330
REFERENCES

1 Lawn JE, Blencowe H, Oza S, et al. Every newborn: progress, priorities, and potential beyond survival. Lancet 2014;384:189-205.

2 Duke T. CPAP: a guide for clinicians in developing countries. Paediatr Int Child Health 2014;34:3-11.

3 Berger TM, Fontana M, Stocker M. The journey towards lung protective respiratory support in preterm neonates. Neonatology 2013;104:265-74.

4 Kamath BD, Macguire ER, McClure EM, et al. Neonatal mortality from respiratory distress syndrome: lessons for low-resource countries. Pediatrics 2011;127:1139-46.

5 Thukral A, Sankar MJ, Chandrasekaran A, et al. Efficacy and safety of CPAP in low- and middle-income countries. J Perinatol 2016;36 Suppl 1:S21-8.

6 Koyamaibole L, Kado J, Qovu JD, et al. An evaluation of bubbleCPAP in a neonatal unit in a developing country: effective respiratory support that can be applied by nurses. J Trop Pediatr 2006;52:249-53.

7 Rojas MA, Lozano JM, Rojas MX, et al. Very early surfactant without mandatory ventilation in premature infants treated with early continuous positive airway pressure: a randomized, controlled trial. Pediatrics 2009;123:137-42.

8 Ballot DE, Chirwa TF, Cooper PA. Determinants of survival in very low birth weight neonates in a public sector hospital in Johannesburg. BMC Pediatr 2010;10:30.

9 Tagare A, Kadam S, Vaidya U, et al. Bubble CPAP versus ventilator CPAP in preterm neonates with early onset respiratory distress--a randomized controlled trial. J Trop Pediatr 2013;59:113-9.

10 Kawaza K, Machen HE, Brown J, et al. Efficacy of a low-cost bubble CPAP system in treatment of respiratory distress in a neonatal ward in Malawi. Malawi Med J 2016;28:131-7.

11 Nahimana E, Ngendahayo M, Magge H, et al. Bubble CPAP to support preterm infants in rural Rwanda: a retrospective cohort study. BMC Pediatr 2015;15:135.

12 Afjeh SA, Sabzehei MK, Khoshnood Shariati M, et al. Evaluation of initial respiratory support strategies in VLBW neonates with RDS. Arch Iran Med 2017;20:158-64.

13 Ho JJ, Subramaniam P, Davis PG. Continuous distending pressure for respiratory distress in preterm infants. Cochrane Database Syst Rev 2015;7:CD002271.

14 Fischer C, Bertelle V, Hohlfeld J, et al. Nasal trauma due to continuous positive airway pressure in neonates. Arch Dis Child Fetal Neonatal Ed 2010;95:F447-51.

15 Hartnett ME, Lane RH. Effects of oxygen on the development and severity of retinopathy of prematurity. J Aapos 2013;17:229-34.

16 Davidson LM, Berkelhamer SK. Bronchopulmonary dysplasia: chronic lung disease of infancy and long-term pulmonary outcomes. $J$ Clin Med 2017;6:4.

17 World Health Organization. Recommendations on interventions to improve preterm birth outcomes. Geneva: World Health Organization, 2015. https://www.ncbi.nlm.nih.gov/books/NBK321160/

18 Ministry of Health and Family Welfare. Care of small and sick newborns in special newborn care units of India. New Delhi: Government of India, 2016.

19 Ministry of Health and Family Welfare. Facility based newborn care operational guidelines. New Delhi: Government of India, 2011.

20 Kiran S, Murki S, Pratap OT, et al. Nasal continuous positive airway pressure therapy in a non-tertiary neonatal unit: reduced need for up-transfers. Indian J Pediatr 2015;82:126-30.

21 Ministry of Health and Family Welfare. List of high priority districts in the country. New Delhi: Government of India, 2015.

22 Donabedian A. Evaluating the quality of medical care. Milbank Mem Fund Q 1966;44:166-206.

23 Sundaram V, Chirla D, Panigrahy N, et al. Current status of NICUs in India: a nationwide survey and the way forward. Indian J Pediatr 2014;81:1198-204.

24 Arai LAdeC, Azevedo RB. Contamination of anesthesia circuits by pathogens. Rev Bras Anestesiol 2011;61:50-9.

25 Gray J, George RH, Durbin GM, et al. An outbreak of Bacillus cereus respiratory tract infections on a neonatal unit due to contaminated ventilator circuits. J Hosp Infect 1999;41:19-22.

26 Kalpoe JS, Hogenbirk K, van Maarseveen NM, et al. Dissemination of Bacillus cereus in a paediatric intensive care unit traced to insufficient disinfection of reusable ventilator air-flow sensors. J Hosp Infect 2008;68:341-7.

27 UNICEF. Toolkit for setting up special newborn care units, stabilisation units and newborn care corners. New York: UNICEF, 2007.

28 British Association of Perinatal Medicine (BAPM). Service standards for hospitals providing neonatal care. London: British Association of Perinatal Medicine, 2010. 
29 Ministry of Health and Family Welfare. Government of India. Indian newborn action plan. Press Information Bureau, Government of India, 2014. https://www.newbornwhocc.org/INAP_Final.pdf

30 Tarnow-Mordi W, Stenson B, Kirby A, et al. Outcomes of two trials of oxygen-saturation targets in preterm infants. $N$ Engl J Med 2016;374:749-60.

31 Sola A, Golombek SG, Montes Bueno MT, et al. Safe oxygen saturation targeting and monitoring in preterm infants: can we avoid hypoxia and hyperoxia? Acta Paediatr 2014;103:1009-18.

32 Urs PS, Khan F, Maiya PP. Bubble CPAP - a primary respiratory support for respiratory distress syndrome in newborns. Indian Pediatr 2009;46:409-11.

33 Padhi TR, Jain L, Behera UC, et al. Retinopathy of prematurity profile and trend over the years: experience from a two tier City in eastern India. Indian Pediatr 2016;53 Suppl 2:S76-9.

34 Rekha S, Battu RR. Retinopathy of prematurity: incidence and risk factors. Indian Pediatr 1996;33:999-1003.

35 Charan R, Dogra MR, Gupta A, et al. The incidence of retinopathy of prematurity in a neonatal care unit. Indian $\mathrm{J}$ Ophthalmol 1995;43:123-6.

36 Gopal L, Sharma T, Ramachandran S, et al. Retinopathy of prematurity: a study. Indian J Ophthalmol 1995;43:59-61.

37 Singh M, Deorari AK, Paul VK, et al. Three-year experience with neonatal ventilation from a tertiary care hospital in Delhi. Indian Pediatr 1993;30:783-9.

38 Koti J, Murki S, Gaddam P, et al. Bubble CPAP for respiratory distress syndrome in preterm infants. Indian Pediatr 2010;47:139-43.

39 Tagare A, Kadam S, Vaidya U, et al. A pilot study of comparison of BCPAP vs. VCPAP in preterm infants with early onset respiratory distress. J Trop Pediatr 2010;56:191-4.

40 Saxena A, Thapar RK, Sondhi V, et al. Continuous positive airway pressure for spontaneously breathing premature infants with respiratory distress syndrome. Indian J Pediatr 2012;79:1185-91.

41 Daga S, Mhatre S, Borhade A, et al. Home-made continuous positive airways pressure device may reduce mortality in neonates with respiratory distress in low-resource setting. J Trop Pediatr 2014;60:343-7.

42 Goel AK, Talwar D, Jain SK. Evaluation of short-term use of nocturnal nasal continuous positive airway pressure for a clinical profile and exercise capacity in adult patients with obstructive sleep apneahypopnea syndrome. Lung India 2015;32:225-32.

43 Agarwal S, Maria A, Roy MK, et al. A randomized trial comparing efficacy of bubble and ventilator derived nasal CPAP in very low birth weight neonates with respiratory distress. J Clin Diagn Res 2016;10:SC09-12.

44 Hendriks H, Kirsten GF, Voss M, et al. Is continuous positive airway pressure a feasible treatment modality for neonates with respiratory distress syndrome in a rural district hospital? J Trop Pediatr 2014;60:348-51.

45 Kirsten GF, Kirsten CL, Henning PA, et al. The outcome of ELBW infants treated with nCPAP and InSurE in a resource-limited institution. Pediatrics 2012;129:e952-9.

46 Pieper $\mathrm{CH}$, Smith J, Maree D, et al. Is nCPAP of value in extreme preterms with no access to neonatal intensive care? J Trop Pediatr 2003;49:148-52.

47 Tapia JL, Urzua S, Bancalari A, et al. Randomized trial of early bubble continuous positive airway pressure for very low birth weight infants. $J$ Pediatr 2012;161:75-80.

48 Rezzonico R, Caccamo LM, Manfredini V, et al. Impact of the systematic introduction of low-cost bubble nasal CPAP in a NICU of a developing country: a prospective pre- and post-intervention study. BMC Pediatr 2015;15:26.

49 Sahni R, Schiaratura M, Polin RA. Strategies for the prevention of continuous positive airway pressure failure. Semin Fetal Neonatal Med 2016;21:196-203.

50 Chattopadhyay MP, Pradhan A, Singh R, et al. Incidence and risk factors for retinopathy of prematurity in neonates. Indian Pediatr 2015;52:157-8. 